\title{
Sex-related demographics in two remnant populations of a dioecious tree llex cornuta (Aquifoliaceae): implications for conservation
}

\author{
Sookyung Shin ${ }^{1,2}$, Hakbong Lee ${ }^{1,3}$, Jei-Wan Lee ${ }^{2}$ and Hyesoon Kang ${ }^{1 *}$
}

\begin{abstract}
Background: Dioecious plant species having both male and female plants have been investigated regarding sexrelated characteristics such as sex ratio, sex-differential resource requirements, and spatial segregation of the sexes. Habitat loss and fragmentation are major threats to the survival of plant populations, but dioecious species are particularly more prone to such habitat degradation than non-dioecious species because of their dimorphic sexual system. We examined the sex-related demographics of two llex cornuta populations being different regarding land use history.
\end{abstract}

Methods: During 2016-2017, we examined I. cornuta trees with a basal diameter $\geq 1.5 \mathrm{~cm}$ in the Yongsu-ri population (YS population) and the Gotjawal Provincial Park population (GP population). Plant sex (male, female, or unsexed) was identified. The tree size (basal diameter and height of the main stem), clonal production (the ramet numbers per genet), and vitality for each clone were measured. The associations between population, sex, tree size, clonal production, and vitality were examined using ANOVAs and contingency table analyses. Finally, point pattern analyses using O-ring statistics were conducted to assess spatial patterns.

Results: Upon excluding unsexed trees, the YS population with 74 trees was significantly male-biased (0.66), while the GP population with only 26 trees had a 1:1 sex ratio. In both populations, males and females did not differ in tree size. Although the mean number of ramets differed significantly between populations, females tended to produce more ramets than males. The proportion of weak trees was significantly higher in the YS than in the GP population. Neither population showed evidence of spatial segregation of the sexes.

Conclusions: The two populations of dioecious I. cornuta are characterized by the small number of trees and relatively high frequencies of non-reproductive trees. Both indicate that these populations are quite susceptible to environmental and genetic stochasticity. On the other hand, the differences between populations in sex ratio, clonal production, and vitality suggest that conservation efforts for I. cornuta need to be population-specific. In order to help recover and enable this vulnerable species to persist, it is necessary to find ways to enhance their sexual reproduction and simultaneously reduce habitat disturbances due to anthropogenic activities.

Keywords: Conservation, Dioecy, llex cornuta, Sex ratio, Sex-related spatial structure

\footnotetext{
* Correspondence: hkang@sungshin.ac.kr

'Department of Biology, Sungshin University, 76 Ga-gil, Dobong-ro,

Gangbuk-gu, Seoul 01133, Republic of Korea

Full list of author information is available at the end of the article
}

(c) The Author(s). 2019 Open Access This article is distributed under the terms of the Creative Commons Attribution 4.0 International License (http://creativecommons.org/licenses/by/4.0/), which permits unrestricted use, distribution, and reproduction in any medium, provided you give appropriate credit to the original author(s) and the source, provide a link to the Creative Commons license, and indicate if changes were made. The Creative Commons Public Domain Dedication waiver (http://creativecommons.org/publicdomain/zero/1.0/) applies to the data made available in this article, unless otherwise stated. 


\section{Background}

Flowering plants have extremely diverse sexual systems, breeding systems, flower morphology, and phenology. These are believed to reflect their adaptability to variable environments. In particular, dioecious plant species having both male and female plants have been investigated regarding sex-related characteristics such as sex ratio variation, sex-differential resource requirements, and spatial segregation of the sexes (SSS) (Obeso 2002; Barrett and Hough 2013; Garbarino et al. 2015). In the diverse dioecious populations and species examined, sex ratios were often female- or male-biased, with the latter being far more common than the former. This was contrary to the theoretical expectation of the 1:1 ratio (Queenborough et al. 2007; Garbarino et al. 2015). Males and females of many dioecious species also differ in growth rate, reproductive age, and mortality, being responsible for skewed sex ratios (Obeso 2002; Cepeda-Cornejo and Dirzo 2010; Kang and Shin 2012). Another issue regarding sex-related characteristics in many dioecious species is clone formation through vegetative means such as suckers and tillers, which form clones of ramets. If clonality negatively affects sexual reproduction, clonality difference between sexes and its genetic consequences may exert significant influence overpopulation or species persistence (Barrrett 2015).

Habitat loss and fragmentation is a major threat to the survival of plant populations (Alofs et al. 2014; Fahrig 2017). Dioecious plants have the reproductive handicap of reduced mate assurance and seed shadows because they have separate male and female plants (Heilbuth et al. 2001; $\mathrm{Yu}$ and $\mathrm{Lu}$ 2011), making them more vulnerable than non-dioecious species to environmental changes (Vamosi and Otto 2002) and climate change (Hultine et al. 2016). Therefore, strategies to conserve dioecious plants must integrate knowledge about their demographic parameters, ecological attributes, and spatial structure based on sex-specific characteristics.

Ilex cornuta (Aquifoliaceae) is a broad-leaved evergreen shrub that belongs to the largest genus ( 405-600 species) of woody dioecious plants (Stevens 2001 onward; Tsang 2005). It is an endemic species of East Asia (Galle 1997), inhabiting South Korea and eastern China. In Korea, I. cornuta occurs in the southern region below $35^{\circ} 37^{\prime} \mathrm{N}$, including Jeolla-do Province on the mainland and Jeju Island in the southern sea of Korea. This species is designated as "vulnerable" by the Korea National Arboretum (2008). Several studies have highlighted the extinction risk of I. cornuta in South Korea (Ko 2004; Kwon et al. 2011). For example, among the nine natural habitats of this species reported on the mainland in previous field surveys (Yim 1979; Lee 1983), only two sites remain two decades later (Ko 2004). One of them is located at Buan (Jeollabuk-do province) and represents the largest mainland population due to legal protection as a Natural Monument since 1962 (No. 122). However, the Buan population contains only male trees (Park et al. 2000). Hong et al. (2015) confirms that all-male trees examined are genetically monomorphic, most likely as a result of asexual reproduction through cuttings or suckers from a single male. These results emphasize that variations of sex ratio and spatial distribution pattern of I. cornuta need to be incorporated with the pattern of clonality.

A couple of or at most several natural populations of $I$. cornuta are present on Jeju Island, South Korea. Because both anthropogenic pressure and climatic change effects are quite severe in a fairly large area of the island (Kang et al. 2008; Lee et al. 2013), similar or greater risks may exist for those populations. Mainland populations are believed to be derived from Jeju populations based on higher genetic variations of internal transcribed spacers (Son et al. 2007). However, ecological information on the distribution and demography of male and female $I$. cornuta trees on Jeju Island is scant. Previous studies on congeneric species (e.g., Obeso et al. 1998; Tsang 2005) showed ecological and physiological dimorphism of male and female trees (genets) even after considering ramet production. We also expect sex-related effects on ecology and vitality in I. cornuta trees of Jeju Island. In this study, we address the following questions: (1) Do the sex ratios deviate significantly from 1:1 at the level of genet?; (2) Do males and females differ for tree sizes such as basal diameter and height; (3) Do clonal production and vitality differ between populations, sexes, and tree size groups? and (4) Are male and female trees spatially segregated? These questions will provide essential information to evaluate the current status and to develop appropriate conservation strategies for vulnerable dioecious species.

\section{Materials and methods \\ Study species and sites}

Ilex cornuta Lindl. \& Paxton (Aquifoliaceae) is a densely foliaged evergreen shrub that can grow up to $3 \mathrm{~m}$ in height (Lee 2003; Son 2008). Leaves are thick and leathery and are usually six-spined on the oblong shape; however, the number of spines varies with a high level of mutations. Flowering occurs between April and May. Male and female flowers clumped in the axils of the second-year branches are 4-merous, about $7 \mathrm{~mm}$ in diameter, and yellow-greenish in color. Male flowers have four long stamens each terminating with an oblong anther and a rudimentary ovary, while female flowers have a large ovary with four carpels and four short staminodes. The nectar and fragrance of flowers indicate that they are insect-pollinated. The red drupes ripen between September and October that are typically dispersed by 
birds. Like many other congeneric species (e.g., I. aquifolium [Obeso et al. 1998]), I. cornuta combines sexual reproduction with a form of vegetative propagation by suckers arising from shallow lateral roots (Lee 1983).

This study was conducted in two I. cornuta populations having different land use histories, although both of them are located on "Gotjawal" terrain that is a volcanic area with scattered larva blocks and thin soils (Fig. 1). First, the Yongsu-ri population (YS population, hereafter) is located near Yongsu Reservoir in Hangyeongmyeon, Jeju-si $\left(33^{\circ} 19^{\prime} \mathrm{N}, 126^{\circ} 10^{\prime} \mathrm{E}\right)$, which is an artificial reservoir built in 1957. I. cornuta population is on the lower part of lava terraces and coexists with a total of 66 plant taxa, including Pinus thunbergii and Sageretia thea (Kwon et al. 2011). The area is close to villages and surrounded by agricultural land. I. cornuta trees remain in open spaces between farmlands (Fig. 2). Data (2008-2017) from Gosan Regional Meteorological Office, which is close to the YS population, showed that the mean monthly temperature ranged from $5.8{ }^{\circ} \mathrm{C}$ in January to $26.5{ }^{\circ} \mathrm{C}$ in August (mean annual temperature: $15.7^{\circ} \mathrm{C}$ ). The mean annual precipitation was $1151.6 \mathrm{~mm}$, peaking in August $(324.1 \mathrm{~mm})$, and a mean annual wind speed of $6.6 \mathrm{~m} / \mathrm{s}$ (Korea Meteorological Administration 2018). Second, the Jeju Gotjawal Provincial Park population (GP population hereafter) is located in Daejeong-eup, Seogwipo-si $\left(33^{\circ}\right.$ $12^{\prime} \mathrm{N}, 126^{\circ} 10^{\prime}$ E). Jeju Gotjawal Provincial Park (area = 154.7 ha) was designated as a protected area in 2011 by the Natural Parks Act for the systematic preservation and management of Gotjawal (Jeju Gotjawal Provincial Park 2018). I. cornuta trees form a population around the observatory in the Provincial Park (Fig. 2). This site apparently has been less disturbed by human activities than the YS population because of its relative remoteness from villages and rocky geology, thereby maintaining a vegetation typical of Gotjawal terrain and supporting high species diversity including various endangered species such as Quercus gilva, Copris tripartitus, and Accipiter gularis (Jeju Gotjawal Provincial Park 2018). According to Daejeong Regional Meteorological Office, the mean monthly temperature (2008-2017) ranged from $5.9{ }^{\circ} \mathrm{C}$ in January to $27.2{ }^{\circ} \mathrm{C}$ in August (mean annual temperature: $16.2{ }^{\circ} \mathrm{C}$ ). The mean annual precipitation was $1456.9 \mathrm{~mm}$, peaking in August $(466.5 \mathrm{~mm})$, and a mean annual wind speed of $3.7 \mathrm{~m} / \mathrm{s}$ (Korea Meteorological Administration 2018). Figure 2 presents the characteristic features of the two I. cornuta populations in Jeju Island, South Korea.

\section{Data collection}

All individuals of $I$. cornuta with a basal diameter $\geq$ $1.5 \mathrm{~cm}$ in the two populations were tagged, and their ecological characteristics (sex, tree size [basal diameter and height of the main stem], clonal production, vitality, and geographic coordinates) were recorded during 2016-2017. Sex was separated into three classes, including male (M), female (F), and unsexed (U; i.e., trees with no sex expression), based on flower morphology and fruiting. Despite the clonal structure, it was relatively easy to identify the trees (genets) and the largest or widest stem (ramet) of each genet (see Fig. 2c). Therefore, tree size was measured by basal diameter and height for the largest stem of each genet, which was treated to be the main stem. Basal diameter was measured to $0.1 \mathrm{~cm}$ accuracy with a vernier caliper at $5 \mathrm{~cm}$ above ground,

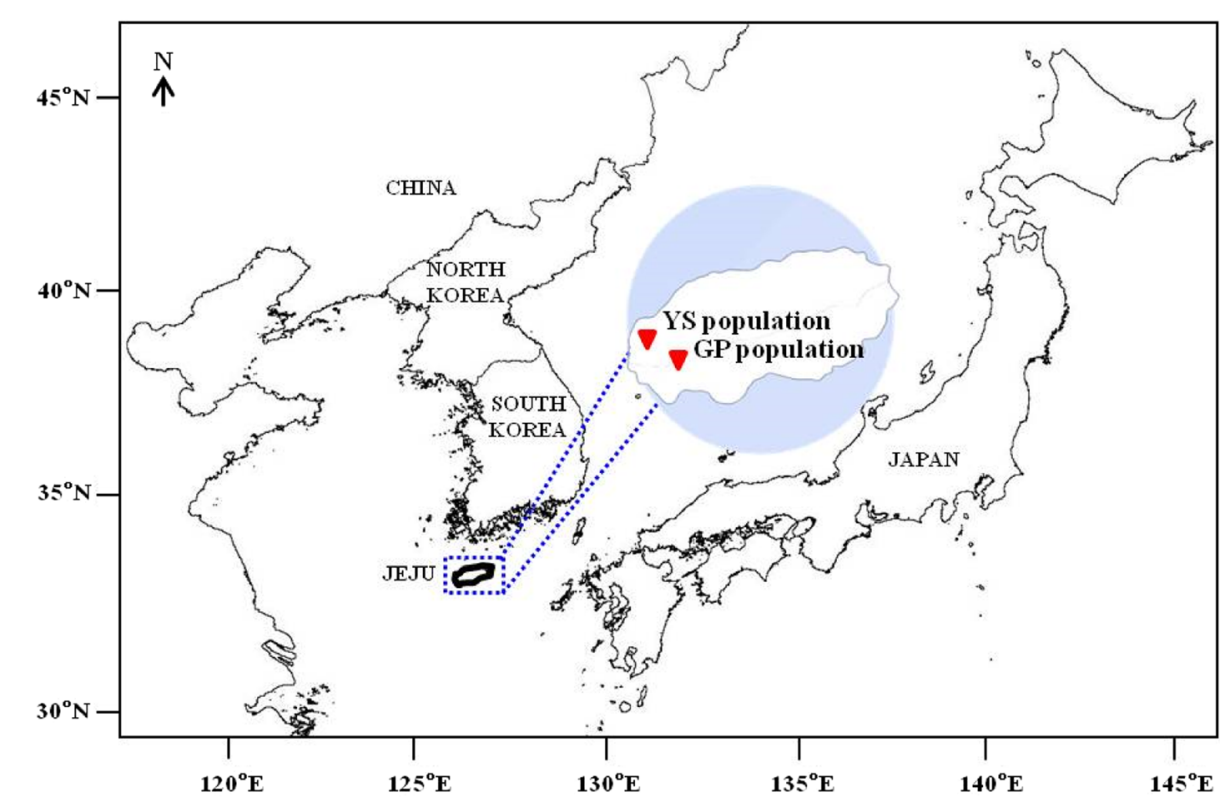

Fig. 1 Location of the two llex cornuta populations examined on Jeju Island, South Korea 

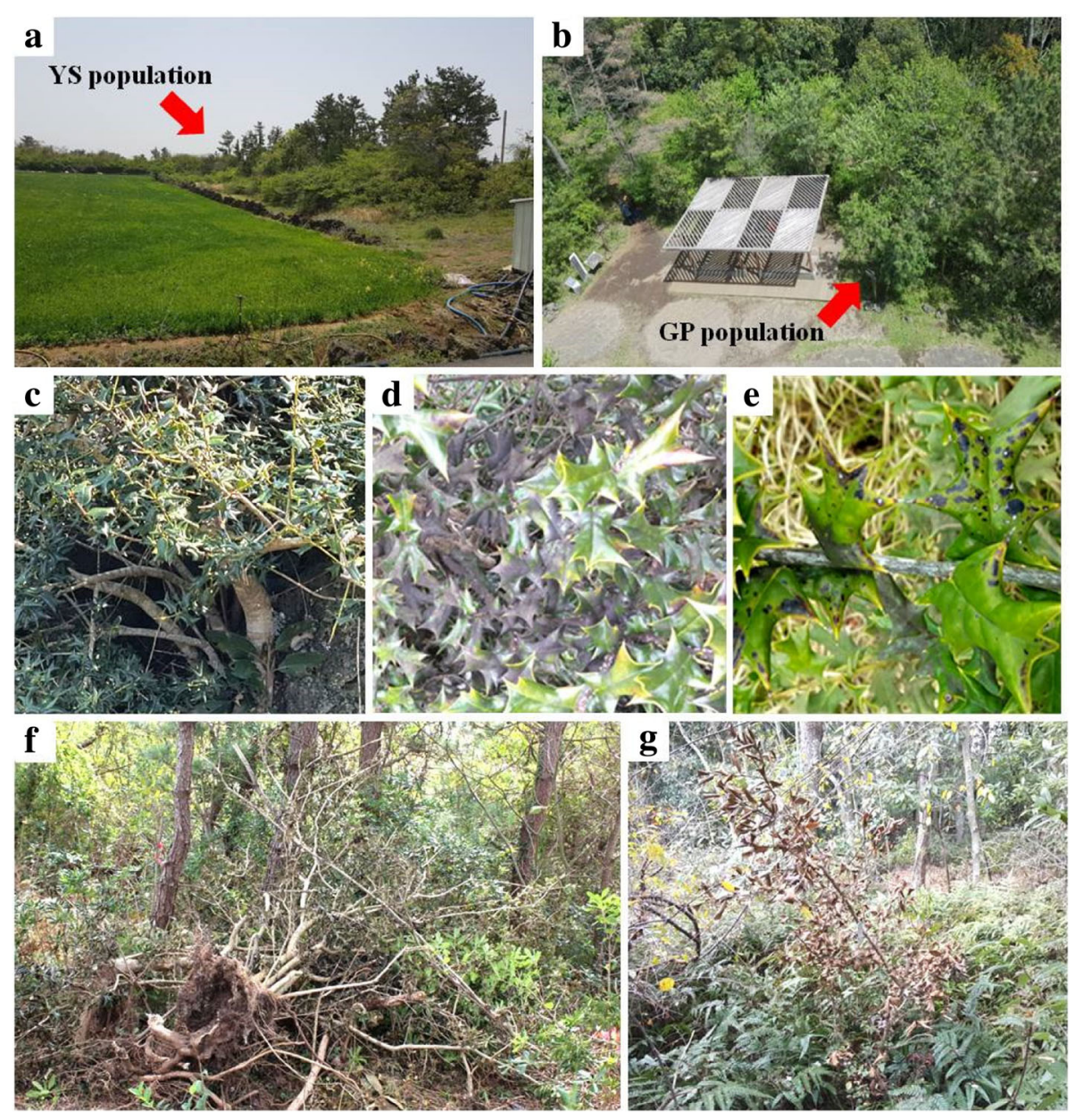

Fig. 2 Wild I. cornuta trees in the two populations on Jeju Island. a Full view of the YS population. b Full view of the GP population. c I. cornuta genets usually formed a clone with several ramets, and the largest ramet in the center was treated as the main stem. $\mathbf{d}$ and $\mathbf{e} \mathbf{l}$. cornuta is experiencing diseases such as powdery mildew and tar spots in the YS population. $\mathbf{f}$ The I. cornuta tree was cut in the YS population. $\mathbf{g}$ The I. cornuta tree was standing dead in the GP population during the survey period (2016-2017)

and tree height was measured to $0.1 \mathrm{~m}$ accuracy with a measuring tape. Clonal production was defined as the number of stems (ramets) per genet, and we counted the number of stems for each tree. Vitality was evaluated based on symptoms of disease, including leaf spot, tar spot, and powdery mildew, and was recorded as the proportion of damaged area on each tree.

\section{Data analyses}

Sex ratio and genet size distribution in the two populations The sex ratio was estimated as the proportion of males divided by all reproductive individuals: males/(males $+\mathrm{fe}-$ males). Values higher than 0.5 indicate male bias. The significance of deviations from an equal sex ratio was tested using a chi-square test. One-way ANOVAs were used to determine differences in tree size such as basal diameter and height between males and females at each population. Basal diameter of the main stem was used as an indicator of tree size because basal diameter and height were significantly correlated in the preliminary analyses (YS population, $r=0.59, N=94$; GP population, $r=0.70$, $N=33 ; P<0.001$ for both). I. cornuta trees were separated into three size classes according to basal diameter: small, $<3.0 \mathrm{~cm}$; middle, $3.0-6.0 \mathrm{~cm}$; large, $\geq 6.0 \mathrm{~cm}$. A two-way ANOVA with tree size as a dependent variable and both population and sex as independent variables was conducted to examine tree size differences between populations and sexes (male, female, and unsexed). Other analyses dealt with sex included only two classes (male and female), if not specifically mentioned.

\section{Clonal production and vitality variation between populations}

The effects of population, sex, and tree size on clonal production were examined simultaneously in a threeway ANOVA, where due to limited sample size only 
two-way interactions were included in the model. In addition, a two-way ANOVA was employed to test the effect of sex and tree size on clonal production in each population. The vitality of trees was separated into three categories: healthy, $<10 \%$ damaged area; medium, 10 $60 \%$; weak, $\geq 60 \%$. Two-way contingency table analyses were conducted to assess the association between vitality and each ecological characteristic (population, sex, and tree size). It was necessary to conduct a four-way contingency table analysis to separate effects of ecological characteristics. However, due to small frequencies in the GP population, we decided to perform a three-way contingency table analysis (vitality $\times \operatorname{sex} \times$ tree size) only in the YS population. All statistical analyses were conducted with SPSS v.16.0 software package (SPSS Inc., Chicago, IL).

\section{Spatial pattern analysis}

The point pattern analyses using O-ring statistics (Wiegand and Moloney 2004) were used to assess spatial patterns in the distribution of reproductive I. cornuta in both populations. The O-ring statistic was calculated as the average density of points in a ring with radius $r$ and a ring width around an individual. Univariate and bivariate point pattern analyses were conducted along the distance scale $r(0-50 \mathrm{~m}$ in YS population; $0-40 \mathrm{~m}$ in GP population). In the univariate spatial pattern of individuals, the null hypothesis was complete spatial randomness. For bivariate spatial interactions between males and females, the null hypothesis was random labeling. Significance of both functions was determined with Monte Carlo simulations. In the univariate pattern using $\mathrm{O}_{11}(r)$ values, if the observed $\mathrm{O}_{11}(r)$ values were greater than, similar to, and less than 95\% confidence intervals obtained 999 Monte Carlo simulations, the distribution patterns were assumed to be clumped, random, and regular, respectively. In the bivariate analyses, if the observed $\mathrm{O}_{12}(r)$ values were greater than or less than $95 \%$ confidence intervals, these indicated significant spatial association or segregation between sexes, respectively. Overlapping confidence intervals indicate spatial independency in the distribution pattern of the sexes. All spatial analyses were performed using PROGRAMITA software (Wiegand and Moloney 2004).

\section{Results}

\section{Sex ratios and tree size distribution of $I$. cornuta trees}

The YS population contained a total of 94 I. cornuta individuals ( $\geq 1.5 \mathrm{~cm}$ in basal diameter), of which 49,25 , and 20 were males, females, and unsexed trees, respectively (Table 1 ). In both populations, $21 \%$ of trees did not flower or fruit during 2016-2017. Including only reproductive trees, the sex ratio was 0.66 , revealing a significant bias towards males $(P=0.008)$. On the other hand, the sex ratio of the GP population did not differ significantly from the expected $1: 1(P=1.000)$ with 13,13 , and 7 trees of each sex, i.e., males, females, and unsexed trees, respectively (Table 1 ).

In the YS population, the mean basal diameter of all trees was $4.6 \pm 3.3 \mathrm{~cm}$, and the mean height was $1.5 \pm$ $0.6 \mathrm{~m}$ (Table 1). Females were slightly larger in basal diameter $(5.1 \mathrm{~cm}$ vs. $4.7 \mathrm{~cm})$ and taller in height $(1.6 \mathrm{~m}$ vs. $1.5 \mathrm{~m})$ than males, but these differences were not significant $(P=0.681$ and 0.365 , respectively). In the GP population, the mean basal diameter was $4.3 \pm 2.0 \mathrm{~cm}$, and the mean height was $1.9 \pm 0.6 \mathrm{~m}$. Similar to the YS population, basal diameter and height differences between sexes were not significant ( $P=0.418$ and 0.390 , respectively). Most $(57.6 \%)$ trees fell in the middle basal diameter group (3.0$6.0 \mathrm{~cm}$ ) (Fig. 3). In a two-way ANOVA using population and sex (male, female, and unsexed) as independent variables, tree size did not differ between populations and sexes $(F=0.227, d f=1$ and $121, P=0.635$ for population; $F=1.785, d f=2$ and $121, P=0.172$ for sex). However, when pooling over males and females as a group of reproductive trees, it had a significantly larger basal diameter than unsexed trees $(4.8 \mathrm{~cm}$ vs. $3.4 \mathrm{~cm})$.

\section{Effect of population, sex, and tree size on clonal production and vitality}

I. cornuta trees (genets) produced 1-12 basal sprouting stems called ramets, forming clones (Table 1; Fig. 2c). In one-way ANOVAs with population, sex, or tree size as an independent variable, a clonal production (i.e., ramet number) difference was detected only between populations (Table 2): the GP population trees had as many as 2.3 times more ramets than those in the YS population $(\overline{\mathrm{X}}=3.9 \pm 2.9$ vs. $1.7 \pm 1.7$, respectively). However, the significant effect of population $\times$ tree size interaction in a three-way ANOVA using population, sex, and tree size as independent variables indicated that mean ramet numbers across size classes were variable between populations (Table 2). Indeed, in the YS population, ramet numbers tended to be independent of tree size $(\overline{\mathrm{X}}=1.8 \pm 2.0,1.7 \pm 1.5,1.7 \pm 1.6$ for small, medium, and large trees, respectively), while in the GP population, small and middle-sized trees possessed a lower number of ramets than large trees $(\overline{\mathrm{X}}=3.2 \pm 0.8,3.3 \pm 2.2,6.0 \pm 4.6$, respectively). Subsequent one-way ANOVAs showed that tree size had no significant effects on ramet numbers in both populations $(F=0.178, d f=2$ and $71, P=0.838, F=2.181$, $d f=2$ and $23, P=0.139$ in the YS and GP population, respectively). In the GP population, small sample size appeared to limit the statistical significance.

Many I. cornuta trees had evidence of disease, including leaf spot, tar spot, and powdery mildew (Fig. $2 \mathrm{~d}$ and e). In two-way contingency table analyses, vitality was significantly associated only with population (Table 3). In the YS 
Table 1 Size distributions of Ilex cornuta male, female, and unsexed trees in the two populations on Jeju Island. $\bar{X} \pm 1$ SD is provided for each variable. Ranges are within parentheses

\begin{tabular}{llllll}
\hline Population & & No. of trees & Basal diameter $(\mathrm{cm})$ & Tree height $(\mathrm{m})$ & No. of ramets/genet \\
\hline YS & Male & 49 & $4.7 \pm 3.2(1.5-16.2)$ & $1.5 \pm 0.7(0.5-3.8)$ & $1.6 \pm 1.4(1-8)$ \\
& Female & 25 & $5.1 \pm 4.0(1.5-20.0)$ & $1.6 \pm 0.7(0.6-3.5)$ & $2.0 \pm 2.0(1-10)$ \\
Unsexed & 20 & $3.5 \pm 2.5(1.5-13.0)$ & $1.2 \pm 0.5(0.5-1.9)$ & $1.5 \pm 0.9(1-4)$ \\
GP & Mean & 94 & $4.6 \pm 3.3$ & $1.5 \pm 0.6$ & $1.7 \pm 1.5$ \\
& Male & 13 & $4.1 \pm 1.8(2.0-7.8)$ & $1.9 \pm 0.4(1.3-2.4)$ & $3.2 \pm 2.0(1-9)$ \\
& Female & 13 & $4.9 \pm 2.4(2.8-10.3)$ & $2.2 \pm 0.7(1.4-3.2)$ & $4.6 \pm 3.0(1-12)$ \\
& Unsexed & 7 & $3.4 \pm 1.2(1.9-5.0)$ & $1.3 \pm 0.4(0.8-12.0)$ & $3.3 \pm 3.6(1-9)$ \\
\hline
\end{tabular}

population, $35.1 \%$ of all reproductive trees belonged to a weak group, whereas in the GP population, $11.5 \%$ of trees belonged to the weak group. In a three-way contingency table analysis (vitality $\times$ tree size $\times$ sex $)$ for the YS population, vitality was significantly associated with tree size $(G=16.97, P=0.002)$ but not with sex $(G=0.44, P=0.802)$. In the YS population, slightly higher or far higher proportion of small trees belonged to the weak group than middlesized and large trees (23\%, 19\%, and 5\%, respectively).

\section{Sex-related spatial distribution patterns of $I$. cornuta trees}

Figure 4 shows the spatial distribution of males, females, and unsexed trees in the two populations. Univariate analyses showed that all reproductive trees in the YS population were clumped (0-18 m, 20-25 m, and 28$32 \mathrm{~m}$ ) or regularly $(41-50 \mathrm{~m})$ distributed at most scales (Fig. 5). When sex was considered, the spatial pattern changed slightly. Male trees were clumped (0-17 $\mathrm{m}$ and $31-32 \mathrm{~m})$ or regularly $(42-50 \mathrm{~m})$ distributed, while females were randomly distributed at all scales, except for
0-8 $\mathrm{m}$ in which they were clumped. Reproductive trees in the GP population were randomly distributed at most scales, except at $0-5 \mathrm{~m}$ and 39-40 m (Fig. 5). Male and female trees were also randomly distributed, except at 2-4 $\mathrm{m}$ and 31-34 $\mathrm{m}$ (clumped), respectively.

Bivariate analyses on the spatial association between sexes showed no spatial segregation in the YS population (Fig. 6). Rather, males and females were weakly grouped at 4-16 m, 25-27 m, and 30-36 m distances. Spatial association between sexes in the GP population was consistently random at all scales (Fig. 6).

\section{Discussion}

This study reveals that the two $I$. cornuta populations exhibit several ecological characteristics that are vulnerable to environmental and genetic factors. In particular, extremely small population size, skewed sex ratio, no flowering of many trees, and low vitality in both or either one population cause deep concerns over the viability of $I$. cornuta populations on Jeju Island. a YS population

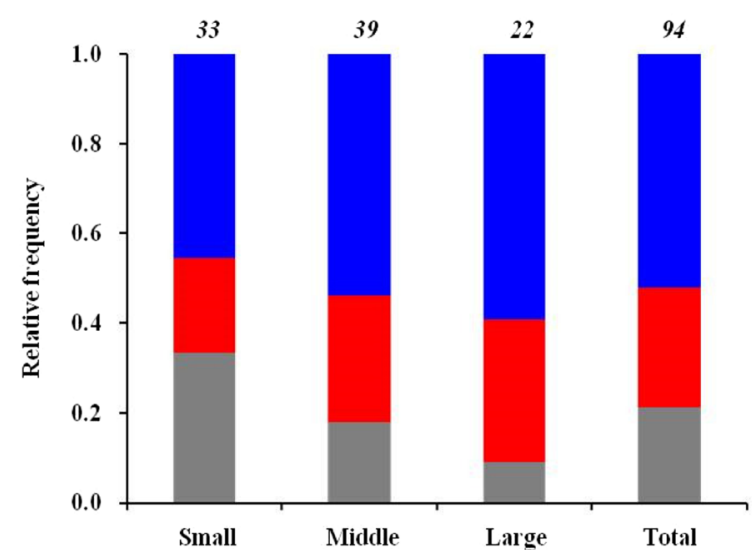

b GP population

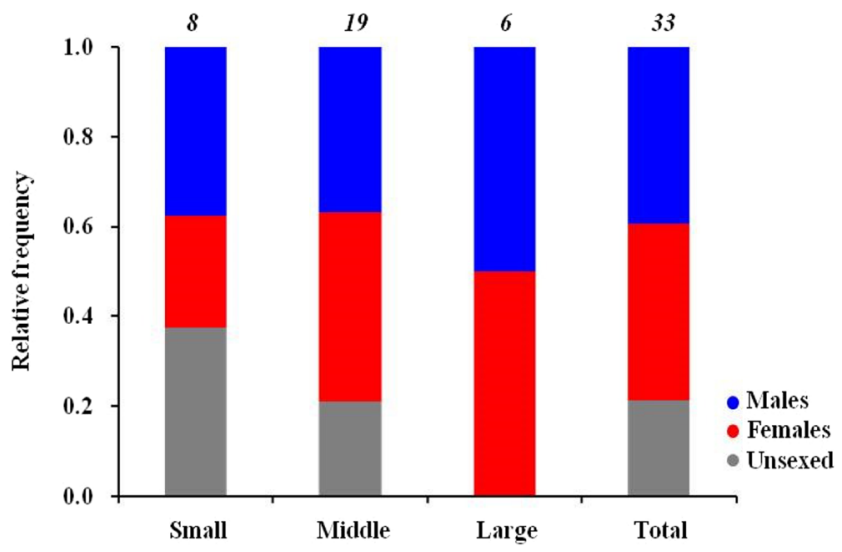

Fig. 3 Relative frequencies of male, female, and unsexed I. cornuta trees across three size classes in the two populations on Jeju Island. a The YS population. $\mathbf{b}$ The GP population. The sample size is indicated above each bar. Tree size: small, $<3.0 \mathrm{~cm}$ basal diameter; middle, $3.0-6.0 \mathrm{~cm}$; large, $\geq 6.0 \mathrm{~cm}$ 
Table 2 One-way ANOVA of the effects of population, sex, and tree size and three-way ANOVA of the effects of population, sex, and tree size (basal diameter) on the clonal production of reproductive llex cornuta trees on Jeju Island

\begin{tabular}{llllll}
\hline Source of variation & df & $F$ & $P$ & $\begin{array}{l}\text { Classes of each } \\
\text { variable }\end{array}$ & $\bar{X} \pm 1$ SD (N) \\
\hline $\begin{array}{llllll}\text { One-way ANOVA } \\
\text { Population }\end{array}$ & 1,99 & 18.606 & 0.000 & YS & $1.7 \pm 1.7(74)$ \\
& & & & GP & $3.9 \pm 2.9(26)$ \\
Sex & 1,99 & 3.146 & 0.079 & Male & $1.9 \pm 1.7(62)$ \\
& & & & Female & $2.9 \pm 2.9(38)$ \\
Tree size & 2,98 & 0.243 & 0.785 & Small & $2.0 \pm 1.9(27)$ \\
& & & & Middle & $2.3 \pm 2.0(48)$ \\
& & & & Large & $2.5 \pm 3.0(25)$
\end{tabular}

Three-way ANOVA

$\begin{array}{llll}\text { Population } & 1,99 & 24.750 & 0.000 \\ \text { Sex } & 1,99 & 3.695 & 0.058 \\ \text { Tree size } & 2,98 & 2.129 & 0.125 \\ \text { Pop } \times \text { sex } & 1,99 & 2.076 & 0.153 \\ \text { Pop } \times \text { tree size } & 2,98 & 4.909 & 0.010 \\ \text { Sex } \times \text { tree size } & 2,98 & 0.491 & 0.614\end{array}$

Tree size: small, $<3.0 \mathrm{~cm}$ for basal diameter; middle, $3.0-6.0 \mathrm{~cm}$; large, $\geq 6.0 \mathrm{~cm}$

\section{Male-biased sex ratio in the YS population}

The sex ratio is used to describe population structure because it contributes to the fitness through sexual reproduction and shows adaptability to particular environmental conditions (Renner and Ricklefs 1995; Vessella et al. 2015). The YS population has a significantly male-

Table 3 Two-way contingency table of vitality vs. population, sex, and tree size of reproductive Ilex cornuta trees on Jeju Island

\begin{tabular}{llll}
\hline & Vitality & Medium & Weak \\
\cline { 2 - 4 } Pealthy & 15 & 26 \\
YS & 33 & 5 & 3 \\
GP & 18 & & \\
Sex & $G=6.604, P=0.039$ & & 12 \\
Male & & 17 & 8 \\
Female & 33 & 12 & \\
Tree size & 18 & & 10 \\
Small & $G=0.333, P=0.847$ & \\
Middle & 16 & 3 & 2 \\
Large & 21 & 17 & \\
\hline
\end{tabular}

biased sex ratio (Table 1). This finding is consistent with the observations that male-biased sex ratios are twice as frequent as female-biased sex ratios in dioecious plant species (Barrett et al. 2010; Field et al. 2013). It is generally assumed that males compared to females tend to inhabit stressful conditions in many species, because of the higher energetic costs of reproduction for females (Obeso 2002; Nuñez et al. 2008). Alternatively, the cost of reproduction is usually believed to result in earlier reproduction, higher growth rates, and longer life spans of males, all contributing to male bias in many dioecious species (Osunkoya 1999; Queenborough et al. 2013). However, in I. cornuta, females tend to be larger (basal diameter and tree height) and produce more ramets, though statistically insignificant. Therefore, it is difficult to state that the current male-biased sex ratio reflects the males' competence in stressful conditions. Furthermore, we have no information for sex-differential establishment and mortality of the YS population following habitat disturbances over years. Further monitoring is needed to find factors causing male bias of $I$. cornuta trees in the YS population.

\section{1:1 sex ratio in the small-sized GP population}

Although the sex ratio did not differ significantly from 1 : 1 in the GP population (13 females and 13 males), this ratio is not likely to reflect that this population is at equilibrium, but more likely to indicate the low statistical power in small samples. Population size is the best predictor of population viability (Schmidt and Jensen 2000) because small populations reduce reproductive success through demographic, environmental, and genetic stochasticity, as well as Allee and edge effects (Lande 1988; Brzyski et al. 2018). Also, previous studies have detected a positive correlation between population size and neutral genetic variation within populations (e.g., Frankham 1996; Leimu et al. 2006). Genetic variation in the GP population is not known, but it may not be high considering the present population size. In such a small population, pollinator visitation rates decrease as patch size decreases (Ashman 2000). The presence of fewer pollinators could be fatal to the survival of I. cornuta populations because they have a mating system of obligate outcrossing involving insect pollination. Consequently, despite the 1:1 sex ratio, the GP population may be on the verge of extinction due to small size and its resulting low sexual reproduction. However, our finding that quite frequently, seedlings around female trees in both populations sheds light on the possibility of recovering this species. Human activities such as cutting and logging (YS population) or trampling (GP population) appear to interrupt the seedlings' survival. For the extremely small-sized GP population, conservation 


\section{a YS population}

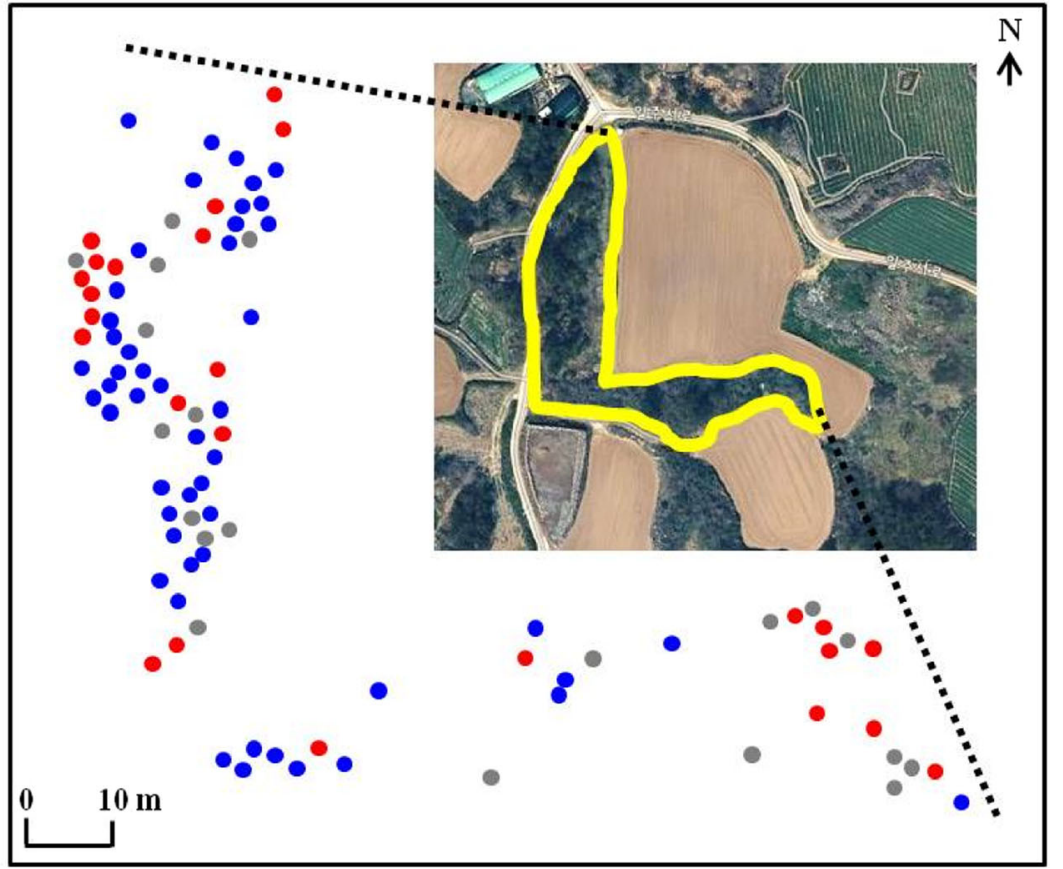

b GP population

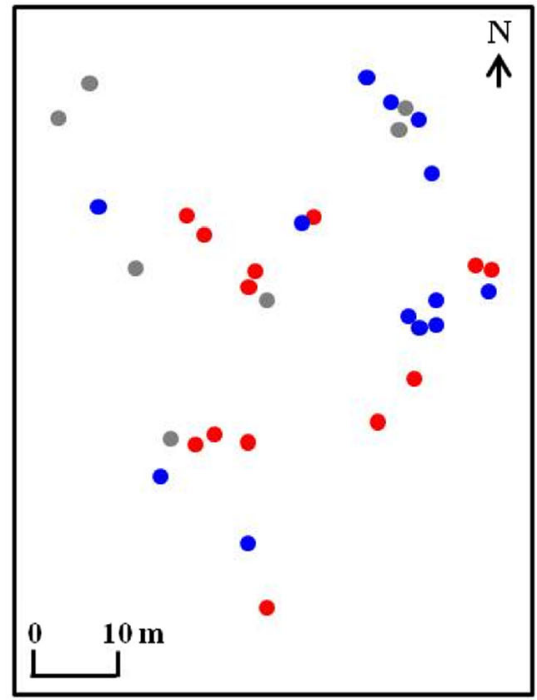

- Males

- Females

- Unsexed

Fig. 4 The spatial distribution of male (red circle), female (blue circle), and unsexed (unsexed) I. cornuta trees (basal diameter $\geq 1.5 \mathrm{~cm}$ ) in the two populations. a The YS population. The upper right aerial photo shows that the population is surrounded by extensive agricultural practices, and the yellow line represents the boundary on which individuals are distributed. b The GP population is located within Jeju Gotjawal Provincial Park, which was established in 2011

a Ys population

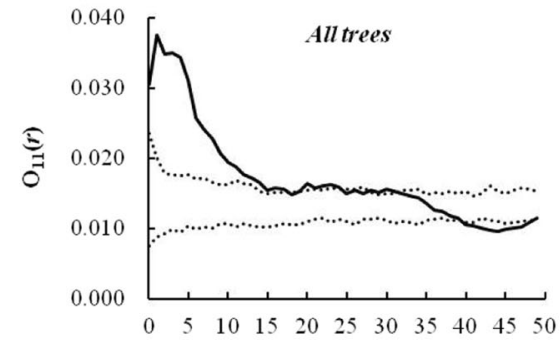

b GP population

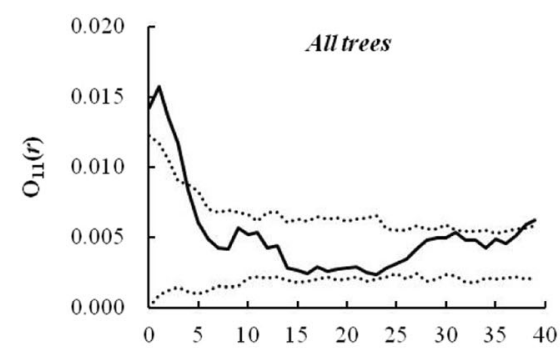

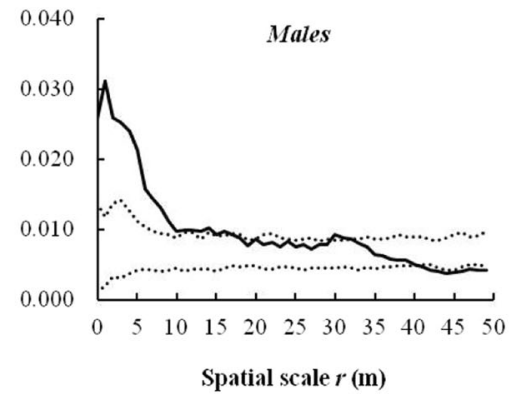
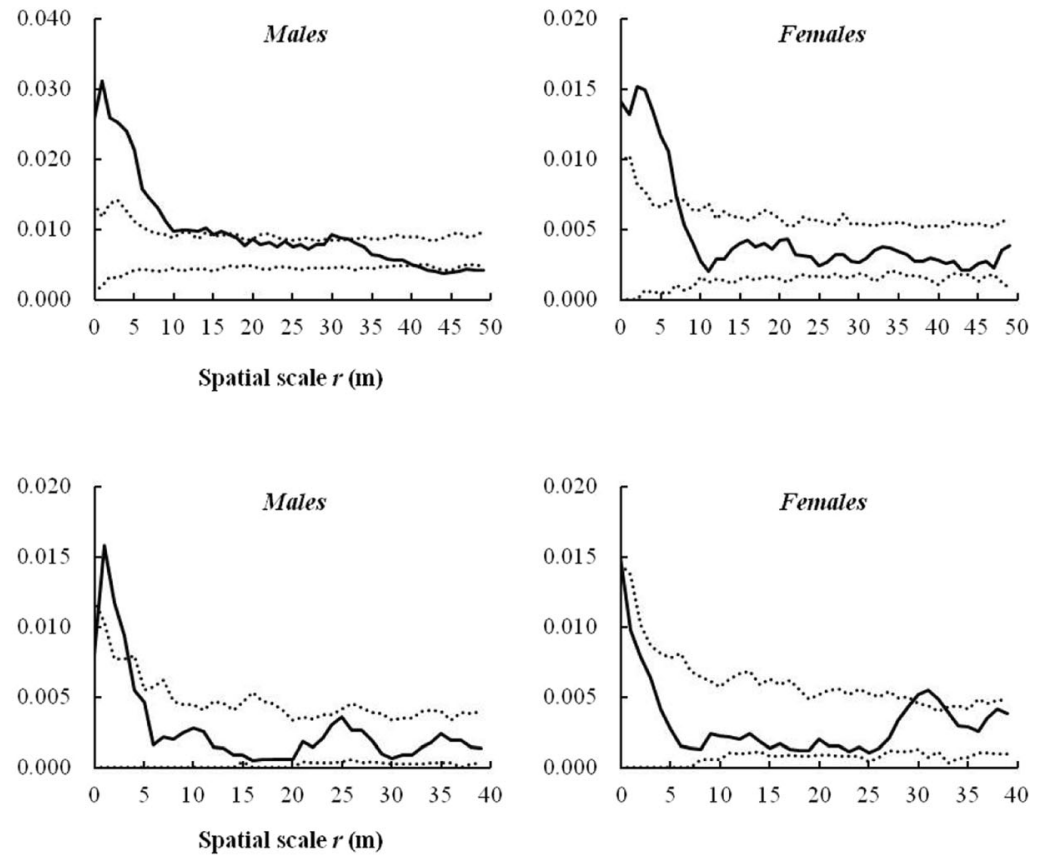

Fig. 5 Univariate analysis of the spatial pattern of I. cornuta trees, considering sex (males and females) using the O-ring statistics $\mathrm{O}_{11}(r)$. a The YS population. b The GP population. Solid lines indicate $\mathrm{O}_{11}(r)$, and dashed lines indicate $95 \%$ confidence envelopes under the complete spatial randomness null model 

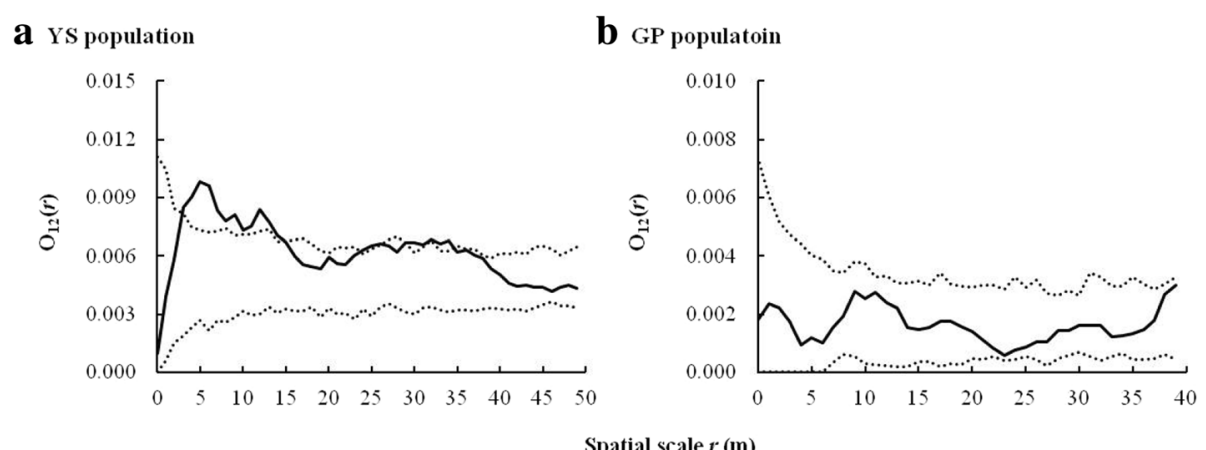

Fig. 6 Bivariate analysis of the spatial pattern of I. cornuta trees, considering sex (males and females) using the O-ring statistics $\mathrm{O}_{12}(r)$. a The YS population. b The GP population. Solid lines indicate $\mathrm{O}_{12}(r)$, and dashed lines indicate $95 \%$ confidence envelopes under the random labeling null model

strategies to increase the sexual reproduction and the resulting seedlings' survival may be most effective.

\section{Factors reducing the effective population size}

The increased extinction risk of dioecious species is also linked to an insufficient number of individuals of the opposite sex, particularly in small and isolated populations (Pannell and Barrett 1998; Munné-Bosch 2015). In contrast to 15 Ilex species in Hong Kong that flower every year with little yearly difference (Tsang 2005), $21 \%$ of $I$. cornuta trees in both populations did not flower or produce fruits for 2 years. We observed flowering and fruiting for only 2 years. The no-flowering status for years and/or an increase in the number of no-flowering trees can accelerate the decline and extinction of $I$. cornuta populations. This process would be much severe for small-sized populations such as the GP population, which has only 26 reproductive trees. Unsexed trees of $I$. cornuta were smaller in size than reproductive trees (Table 1; Fig. 3). They also generally had a bad appearance with damaged branches and little leaves. Indeed, $80 \%$ of the unsexed trees were moderate or weak in vitality due to pest infection (data not shown). Reproductive status in several dioecious tree species is a strong indicator of environmental stress (Hultine et al. 2007). For example, over half of mature trees remained non-reproductive in a stressed population of Populus deltoides var. wislizenii, with many trees switching from reproductive to non-reproductive status in response to environmental stress (Rowland and Johnson 2001). Such sex change or switching between reproductive and non-reproductive status was not observed during our study period for two years. Studies on the causes and consequences of no-flowering in $I$. cornuta populations seem to be first step to increase the effective population size of the already rare $I$. cornuta trees.

\section{Implications of clonal production and vitality}

Clonality is an adaptive strategy used by plants in harsh environments (Bond and Midgley 2001; Barrett 2015). For example, Salix species often exhibit high clonal growth in nutrient-poor sites (Douhovnikoff et al. 2005; Ueno et al. 2007). In I. cornuta populations, genets produced one to 12 ramets forming a clone. I. cornuta trees in the GP population formed 2.2 times more ramets than those in the YS population $(3.8 \pm 3.0$ and $1.7 \pm 1.5$ for GP and YS populations, respectively). Since trees in the two populations do not differ in basal diameter or tree height, ramet number variation may not be an outcome due to tree size allometry relating to basal diameter or height. Instead, it may reflect the adaptive response of I. cornuta trees in each population. Although both populations grow on stressful Gotjawal terrain, land use history or the magnitude of habitat disturbances are quite different, perhaps being responsible for the clonality difference between populations. The YS population, being close to villages, has been heavily used by agricultural practices, and as a result, low and scattered vegetation is present, perhaps allowing sufficient light penetration. On the other hand, the GP population is distant from villages and maintains its almost original vegetation, including I. cornuta and woody vines, which are intermingled with each other and usually under the canopy of various deciduous and evergreen trees. In such a situation, reduced sexual reproduction may result in higher vegetative reproduction since these two modes of reproduction show a trade-off relationship (Van Drunen and Dorken 2012; Barrett 2015). In I. cornuta trees, females produce more ramets in both populations, though it was only marginally significant. This pattern contrasts to some previous studies. For example, male Lindera triloba trees showed a significant increase of the number of ramets compared to females (Matsushita and Tomaru 2012). Clonality variation of I. cornuta trees between populations and sexes in Gotjawal terrain would 
provide a good opportunity to confirm the ecological and evolutionary implications of clonal formation in this dioecious species.

In general, females are more susceptible to abiotic and biotic stresses with fungal infections occurring more frequently on females (Kaltz and Shykoff 2001; Zhang et al. 2009). For example, females of Salix viminalis are subject to more severe fungal infections than males in both field experiments (Moritz et al. 2016). In our two-way contingency table analyses, however, vitality differed only between populations and tree sizes (Table 3). Almost three times higher proportion of trees in the YS population than that in the GP population belonged to weak group (35.1\% vs. $11.5 \%)$. This result indicates that diseased trees are more in number in disturbed habitats than in undisturbed habitats. Then, in the YS population, conservation efforts should focus to reduce the anthropogenic activities. In our previous study (Kang and Shin 2012), the vitality of female Torreya nucifera trees is significantly upgraded compared to males, as a result of management activities such as removing of competing trees and climber coverage. If I. cornuta females respond similarly for reducing habitat disturbances, it will contribute to recover the 1:1 sex ratio and female reproductive success.

\section{Spatial distribution patterns related to sex}

Sexual segregation of the sexes (SSS) has been reported in $>30$ dioecious species from 20 families (Barrett and Hough 2013). In most cases, male-biased sex ratios are reported in more stressful sites (Bierzychudek and Eckhart 1988; Mercer and Eppley 2010). Our bivariate point pattern analysis did not detect any SSS (Fig. 6). SSS has mostly been observed in herbaceous plants (e.g., Eppley 2005), and rarely in shrubs (Zhang et al. 2010) and trees (Garbarino et al. 2015) associated with microhabitat differences such as resource gradient. However, in the highly diverse and small-scale microhabitats of the Gotjawal terrain, where the YS and GP populations are located, resource gradients in moisture or soil nutrients are unlikely to form. Shin et al. (2017) also could not find SSS pattern of Torreya nucifera distributed on Gotjawal terrain in Jeju Island. There were limited numbers of trees in the GP population, which possibly reduced the power of the spatial analysis. The YS population is also subject to major anthropogenic interference, with more than $70 \%$ of individuals being damaged by cutting activity and disease. For example, part of the habitat was destroyed by the removal of pine trees through Pine Wilt Disease, with most I. cornuta trees in this area disappearing. Thus, SSS could not be expected in either population.

\section{Conclusions}

This study reveals the population structure in relation to the sexual system of dioecious tree $I$. cornuta on
Jeju Island, South Korea. The two remnant populations examined, having different land use histories, are similar regarding the non-reproductive trees, i.e., one fifth of all trees no-flowering or no-fruiting for two years. However, they exhibited differences in sexrelated characteristics such as sex ratio, clonal production, and vitality, implying that conservation efforts for I. cornuta need to be population-specific. The YS population is at risk because of the low number of female individuals and low vitality. I. cornuta trees in the GP population present quite a different conservation problem, i.e., extremely small population size of only 26 reproductive trees. Population persistence, almost certainly, depends on the number of females that are fertilized and the number of seeds produced (Groom 2001), and seedling survival. Despite unfavorable habitat conditions, seedlings were present but their establishment seems not to be successful in both populations. Then, in order to increase the population size, conservation efforts for the YS populations should focus to prevent agricultural land expansion and to improve vitality of trees, whereas for the GP population, strategies to enhance sexual reproduction, and seedling establishment would be critical. During the study period, we confirmed the sporadic distribution of I. cornuta trees in areas along the western coast of Jeju Island. The question on the source of these trees would be rewarding to understand the genetic diversity and ultimately to improve the adaptability of $I$. cornuta populations. We also recommend to investigate the effects of human land use change on other native and endangered species in Jeju Island.

\section{Abbreviations}

GP population: Gotjawal Provincial Park population; SSS: Spatial segregation of sexes; YS population: Yongsu-ri population

\section{Acknowledgements}

We thank anonymous reviewers for helpful comments on the drafts of this article. Dr. C-S. Kim kindly provided information for the locations of I. cornuta populations on Jeju Island.

\section{Authors' contributions}

SS conducted the field study and the data analysis and wrote the manuscript. HL conducted field survey. JWL reviewed the manuscript. HK conceived the study and examined the manuscript. All authors read and approved the final manuscript.

\section{Funding}

This study was supported by the Sungshin University Research Grant to HK (Grant no. 2017-1-11-062/1).

Availability of data and materials

The datasets generated during and/or analyzed during the current study are available from the corresponding author on reasonable request.

Ethics approval and consent to participate Not applicable. 


\section{Consent for publication}

Not applicable.

\section{Competing interests}

The authors declare that they have no competing interests.

\section{Author details}

${ }^{1}$ Department of Biology, Sungshin University, 76 Ga-gil, Dobong-ro, Gangbuk-gu, Seoul 01133, Republic of Korea. ${ }^{2}$ Department of Forest Bioresources, National Institute of Forest Science, Suwon 16631, Republic of Korea. ${ }^{3} \mathrm{G}$ wangneung Forest Conservation Center, Korea National Arboretum, Pocheon 11186, Republic of Korea.

\section{Received: 15 July 2019 Accepted: 24 July 2019}

Published online: 03 September 2019

\section{References}

Alofs KM, González AV, Fowler NL. Local native plant diversity responds to habitat loss and fragmentation over different time spans and spatial scales. Plant Ecol. 2014. https://doi.org/10.1007/s11258-014-0372-5.

Ashman TL. Pollinator selectivity and its implications for the evolution of dioecy and sexual dimorphism. Ecology. 2000. https://doi.org/10.1890/0012-9658(2 000)081[2577:PSAllF]2.0.CO;2.

Barrett SCH. Influences of clonality on plant sexual reproduction. PNAS. 2015. https://doi.org/10.1073/pnas.1501712112.

Barrett SCH, Hough J. Sexual dimorphism in flowering plants. J Exp Bot. 2013. https://doi.org/10.1093/jxb/ers308.

Barrett SCH, Yakimowski SB, Field DL, Pickup M. Ecological genetics of sex ratios in the plant populations. Phil Trans R Soc B. 2010. https://doi.org/10.1098/ rstb.2010.0002.

Bierzychudek P, Eckhart V. Spatial segregation of the sexes of dioecious plants. Am Nat. 1988. https://doi.org/10.1086/284836

Bond WJ, Midgley JJ. Ecology of sprouting in woody plants: the persistence niche. Trends Ecol Evol. 2001. https://doi.org/10.1016/S0169-5347(00)02033-4.

Brzyski JR, Stieha CR, McLetchie DN. The impact of asexual and sexual reproduction in spatial genetic structure within and between populations of the dioecious plant Marchantia inflexa (Marchantiaceae). Ann Bot. 2018. https://doi.org/10.1093/aob/mcy106.

Cepeda-Cornejo V, Dirzo R. Sex-related differences in reproductive allocation, growth, defense and herbivory in three dioecious neotropical plams. PLoS One. 2010. https://doi.org/10.1371/journal.pone.0009824.

Douhovnikoff V, McBride JR, Dodd RS. Salix exigua clonal growth and population dynamics in relation to disturbance regime variation. Ecology. 2005. https:// doi.org/10.1890/04-0257.

Eppley SM. Spatial segregation of the sexes and nutrients affect reproductive success in a dioecious wind-pollinated grass. Plant Ecol. 2005. https://doi. org/10.1007/s11258-005-6142-7.

Fahrig L. Ecological responses to habitat fragmentation per se. The Annu Rev Ecol Evol Syst. 2017. https://doi.org/10.1146/annurev-ecolsys-110316-022612.

Field DL, Pickup M, Barrett SCH. Comparative analyses of sex-ratio variation in dioecious flowering plants. Evolution. 2013. https://doi.org/10.1111/ evo.12001.

Frankham R. Relationship of genetic variation to population size in wildlife. Conserv Biol. 1996. https://doi.org/10.1046/j.1523-1739.1996.10061500.x.

Galle FC. Hollies: the genus Ilex. Portland: Timber Press; 1997.

Garbarino M, Weisberg PJ, Bagnara L, Urbinati C. Sex-related spatial segregation along environmental gradients in the dioecious conifer. For Ecol Manag. 2015. https://doi.org/10.1016/j.foreco.2015.09.009.

Groom MJ. Consequences of subpopulation isolation for pollination, herbivory, and population growth in Clarkia concinna concinna (Onagraceae). Biol Conserv. 2001. https://doi.org/10.1016/S0006-3207(00)00207-X.

Heilbuth JC, Ilves KL, Otto SP. The consequences of dioecy for seed dispersal: modeling the seed-shadow handicap. Evolution. 2001. https://doi.org/1 0.1111/j.0014-3820.2001.tb00605.x.

Hong KN, Park YJ, Lee JW, Kim YM. Genetic monomorphism of the natural Ilex cornuta community at the northern range limit in Buan, Jeollanam-do in Korea revealed by AFLP markers. J Korean For Soc. 2015; doi:https://doi.org/1 0.14578/jkfs.2015.104.2.187.

Hultine KR, Bush SE, West AG, Ehleringer JR. Population structure, physiology and ecohydrological impacts of dioecious riparian tree species of western North America. Oecologia. 2007. https://doi.org/10.1007/s00442-007-0813-0.
Hultine KR, Grady KC, Wood TE, Shuster SM, Stella JC, Whitham TG. Climate change perils for dioecious plant species. Nature Plants. 2016. https://doi. org/10.1038/NPLANTS.2016.109.

Jeju Gotjawal Provincial Park. http://jejugotjawal.or.kr/default/index.php?cid=15. Accessed 21 Feb 2018.

Kaltz O, Shykoff JA. Male and female Silene latifolia plants differ in per-contact risk of infection by a sexually transmitted disease. J Ecol. 2001. https://doi.org/1 0.1046/j.1365-2745.2001.00527.x.

Kang H, Kim H, Chang E. Landscape analysis of the Hallasan National Park in a Juju Island biosphere reserve: fragmentation pattern. Korean J Environ Ecol. 2008:22:309-19.

Kang H, Shin S. Sex ratios and spatial structure of the dioecious tree Torreya nucifera in Jeju Island. Korea J Ecol Environ. 2012. https://doi.org/10.5141/ JEFB.2012.015.

Ko MH. Chinese Holly's community structure in Korean peninsula. MS Thesis. Yeungnam University, Gyeongsan, South Korea. 2004.

Korea Meteorological Administration. Climate information. http://sts.kma.go.kr/ jsp/home/contents/main/main.do. Accessed 21 Feb 2018.

Korea National Arboretum. Rare plants data book in Korea. Daejeon: Korea Forest Service; 2008.

Kwon HJ, Lee JH, Kim MY, Lee JH, Song HK. Vegetation structure and soil properties of Ilex cornuta population in Jeju Island. Korean J Environ Ecol. 2011;25:10-6.

Lande R. Genetics and demography in biological conservation. Science. 1988. https://doi.org/10.1126/science.3420403.

Lee JS. Studies on the natural distribution and ecology of Ilex cornuta Lindley et Pax. In Korea. J Korean For Soc. 1983:62:24-42.

Lee SH, Nam KW, Jeong JY, Yoo SJ, Koh YS. The effects of climate change and globalization on mosquito vectors: evidence from Jeju Island, South Korea on the potential for Asian Tiger mosquito (Aedes albopictus) influxes and survival from Vietnam rather than Japan. PLoS One. 2013. https://doi.org/1 0.1371/journal.pone.0068512.

Lee TB. Coloured Flora of Korea. Seoul: Hyangmoonsa; 2003.

Leimu R, Mutikainen PIA, Koricheva J, Fischer M. How general are positive relationships between plant population size, fitness and genetic variation? Ecol. 2006. https://doi.org/10.1111/j.1365-2745.2006.01150.x.

Matsushita M, Tomaru N. Differences in clonal integration between the sexes: long-term demographic patterns in the dioecious, multi-stemmed shrub Lindera triloba. Botany. 2012. https://doi.org/10.1139/b2012-074.

Mercer CA, Eppley SM. Inter-sexual competition in a dioecious grass. Oecologia. 2010. https://doi.org/10.1007/s00442-010-1675-4.

Moritz KK, Björkman C, Parachnowitsch AL, Stenberg JA. Female Salix viminalis are more severely infected by Melampsora spp. but neither sex experiences associational effects. Ecol Evol. 2016. https://doi.org/10.1002/ece3.1923.

Munné-Bosch S. Sex ratios in dioecious plants in the framework of global change. Environ Exper Bot. 2015. https://doi.org/10.1016/j.envexpbot.2014.08.007.

Nuñez Cl, Nuñez MA, Kitzberger T. Sex-related spatial segregation and growth in a dioecious conifer along environmental gradients in northwestern Patagonia. Ecoscience. 2008;15:73-80.

Obeso JR. The costs of reproduction in plants. New Phytol. 2002. https://doi.org/1 0.1046/j.1469-8137.2002.00477.x.

Obeso JR, Santullano MA, Retuerto R. Sex ratio, size distributions and sexual dimorphism in the dioecious tree Ilex aquifolium (Aquifoliaceae). Am J Bot. 1998. https://doi.org/10.2307/2446488.

Osunkoya OO. Population structure and breeding biology in relation to conservation in the dioecious Gardenia actinocarpa (Rubiaceae) - a rare shrub of North Queensland rainforest. Biol Conserv. 1999. https://doi.org/10.1016/ S0006-3207(98)00115-3.

Pannell JR, Barrett SCH. Baker's law revisited: reproductive assurance in a metapopulation. Evolution. 1998. https:/doi.org/10.1111/j.1558-5646.1998.tb03691.x.

Park CM, Seo BS, Kim KH, Park JM, Lim SJ. Inhabitation environments and growth conditions of llex cornuta community in Pyonsanbando. J Korean Inst Trad Landsc Arch. 2000;18:100-15.

Queenborough SA, Burslem DFRP, Garwood NC, Valencia R. Determinants of biased sex ratios and inter-sex costs of reproduction in dioecious tropical forest trees. Am J Bot. 2007. https://doi.org/10.3732/ajb.94.1.67.

Queenborough SA, Humphreys AM, Valencia R. Sex-specific flowering patterns and demography of the understorey rain forest tree Iryanthera Hostmannii (Mysticaeae). Trop Conserv Sci. 2013. https://doi.org/10.1177/194008291300600504.

Renner SS, Ricklefs RE. Dioecy and its correlates in the flowering plants. Am J Bot. 1995. https://doi.org/10.1002/j.1537-2197.1995.tb11504.x. 
Rowland DL, Johnson NC. Sexual demographics of riparian populations of Populus deltoides: can mortality be predicted from a change in reproductive status? Botany. 2001. https://doi.org/10.1139/b01-049.

Schmidt K, Jensen K. Genetic structure and AFLP variation of remnant populations in the rare plant Pedicularis palustris (Scrophulariaceae) and its relation to population size and reproductive components. Am J Bot. 2000. https://doi.org/10.2307/2656854.

Shin S, Lee SG, Kang H. Spatial distribution patterns of old-growth forest of dioecious tree Torreya nucifera in rocky Gotjawal terrain of Jeju Island. South Korea J Ecol Environ. 2017. https://doi.org/10.1186/s41610-017-0050-3.

Son SW. A phylogenetic study of the genus Ilex in Korea. MS Thesis. Yeungnam University, Gyeongsan, South Korea. 2008.

Son SW, Kim JH, Kim YS, Park SJ. ITS sequence variation in populations of Ilex cornuta (Aquifoliaceae). Korean J PI Taxon. 2007; doi:https://doi.org/10.11110/ kjpt.2007.37.2.131

Stevens PF (2001 Onward). Angiosperm phylogeny website. Version 14, July 17. http://www.mobot.org/MOBOT/research/APwed/. Accessed 27 June 2019.

Tsang CA. The ecology of llex species in Hongkong. Ph.D. Dissertation. The University of Hong Kong, Hong Kong, China. 2005.

Ueno N, Suyama Y, Seiwa K. What makes the sex ratio female-biased in the dioecious tree Salix sachalinensis? J Ecol. 2007. https://doi.org/10.1111/ j.1365-2745.2007.01269.x.

Vamosi JC, Otto SP. When looks can kill: the evolution of sexually dimorphic floral display and the extinction of dioecious plants. Proc Royal Soc B. 2002. https://doi.org/10.1098/rspb.2002.2004.

Van Drunen WE, Dorken ME. Trade-offs between clonal and sexual reproduction in Sagittaria latifolia (Alismataceae) scale up to affect the fitness of entire clones. New Phytol. 2012. https://doi.org/10.1111/j.1469-8137.2012.04260.x.

Vessella F, Salis A, Scire M, Piovesan G, Schirone B. Natural regeneration and gender-specific spatial pattern of Taxus baccata in an old-growth population in Foresta Umbra (Italy). Dendrobiology. 2015; doi:https://doi.org/10.12657/ denbio.073.008.

Wiegand T, Moloney AK. Rings, circles, and null-models for point pattern analysis in ecology. Oikos. 2004. https://doi.org/10.1111/j.0030-1299.2004.12497.x.

Yim KB. Variation of genus Ilex in Korea and their ornamental values. J Korean For Soc. 1979;42:1-38.

Yu L, Lu J. Does landscape fragmentation influence sex ratio of dioecious plants? A case study of Pistacia chinensis in the Thousand-Island lake region of China. PLoS One. 2011. https://doi.org/10.1371/journal.pone.0022903.

Zhang C, Zhao X, Gao L, Von Gadow K. Gender-related distributions of Fraxinus mandshurica in secondary and old-growth forests. Acta Oecol. 2010. https:// doi.org/10.1016/j.actao.2009.10.001

Zhang S, Lu S, Xu X, Korpelainen H, Li C. Changes in antioxidant enzyme activities and isozyme profiles in leaves of male and female Populus cathayana infected with Melampsora larici-populina. Tree Physiol. 2009;30:116-28.

\section{Publisher's Note}

Springer Nature remains neutral with regard to jurisdictional claims in published maps and institutional affiliations.

Ready to submit your research? Choose BMC and benefit from:

- fast, convenient online submission

- thorough peer review by experienced researchers in your field

- rapid publication on acceptance

- support for research data, including large and complex data types

- gold Open Access which fosters wider collaboration and increased citations

- maximum visibility for your research: over $100 \mathrm{M}$ website views per year

At BMC, research is always in progress.

Learn more biomedcentral.com/submissions 